\title{
Outcomes of salvage radiotherapy for recurrent prostate cancer after radical prostatectomy
}

\author{
Eric KC Lee *, WH Mui, Adrian W Chan, Y Tung, Frank CS Wong
}

\section{A B S T R A C T}

Introduction: Salvage radiotherapy (SRT) provides effective biochemical control for patients with prostate cancer who have prostate-specific antigen (PSA) failure after radical prostatectomy. However, the effect of SRT on long-term clinical outcomes remains unknown. Therefore, we report the natural history of patients treated with SRT.

Methods: We identified 84 Chinese patients with prostate cancer treated with SRT to the prostatic fossa alone during 2006-2017 at Tuen Mun Hospital, Hong Kong. Survival was calculated using KaplanMeier method. Log rank test and Cox regression were used to determine significance of clinical parameters with outcomes.

Results: Median SRT dose given was 70 Gy (range, 64-76 Gy). Median pre-SRT PSA level was $0.4 \mathrm{ng} / \mathrm{mL}$ (0.2-7.4 ng/mL). After SRT, 47 (56\%) patients had undetectable $(<0.1 \mathrm{ng} / \mathrm{mL})$ PSA levels. After median follow-up of 48 months ( 2 months to 10 years), 25 (30\%) patients had further biochemical progression. Subsequently, 12 patients received androgen deprivation therapy and nine (11\%) developed distant metastasis. The 5-year biochemical progression-free
$86.7 \%$, respectively. Early PSA failure after radical prostatectomy (hazard ratio $=7.4$ ), negative surgical margin (hazard ratio $=2.7$ ), positive extracapsular extension (hazard ratio=4.6), and detectable PSA levels after SRT (hazard ratio=17.3) were associated with lower biochemical progression-free survival after SRT.

Conclusions: High-dose SRT with intensitymodulated radiotherapy/volumetric modulated arc radiotherapy is an effective local treatment that can prevent distant metastasis and avoid the need for androgen deprivation therapy in Chinese patients who have PSA failure after radical prostatectomy.

\section{Hong Kong Med J 2018;24:218-25 \\ DOI: 10.12809/hkmj176888 \\ EKC Lee *, MB, ChB, FHKAM (Radiology) \\ WH Mui, MB, BS, FHKAM (Radiology) \\ AW Chan, MB, BS, FRCR \\ Y Tung, MB, BS, FHKAM (Radiology) \\ FCS Wong, MB, ChB, FHKAM (Radiology)}

Department of Clinical Oncology, Tuen Mun Hospital, Tuen Mun, Hong Kong

* Corresponding author: leekachai2000@yahoo.com.hk

New knowledge added by this study

- Better biochemical progression-free survival after salvage radiotherapy (SRT) can be achieved through higher radiation doses and better selection of patients.

- Patients with prostate-specific antigen (PSA) failure $\leq 24$ months after radical prostatectomy, negative surgical margin, positive extracapsular extension, or detectable PSA after SRT are more likely to develop biochemical progression after SRT.

Implications for clinical practice or policy

- Distant metastasis is more likely to occur in patients with extracapsular extension, patients who cannot achieve biochemical complete response, and patients who develop biochemical progression within 1 year of SRT.

- For these patients, close monitoring for distant metastasis may be needed.

\section{Introduction}

Prostate cancer $(\mathrm{PCa})$ is the most common noncutaneous malignancy among men in western countries, and is the third most common cancer among men in Hong Kong. ${ }^{1}$ Increasing public awareness in the Chinese community, as well as the common use of prostate-specific antigen (PSA) tests by primary health physicians, have led to detection of $\mathrm{PCa}$ at an earlier stage, when it is amenable to either radical surgery or radiotherapy (RT). ${ }^{2}$ Because of recent advancements in operative management, such as robotic-assisted laparoscopic prostatectomy, ${ }^{3}$ many patients have found radical prostatectomy (RP) the preferred treatment option. Nevertheless, adjuvant radiotherapy (ART) to the prostatic fossa is indicated postoperatively in cases with positive surgical margin (SM), or residual disease from extracapsular extension (ECE). Alternatively, patients may receive salvage radiotherapy (SRT) when there is PSA failure, defined as any detectable and rising PSA level after RP.

Currently, ART is still being compared 
with SRT in three randomised controlled trials (RADICALS, RAVES, GETUG-AFU 17). ${ }^{4-6}$ While the results of these European and Australasian studies are still pending, the American Society for Radiation Oncology/American Urological Association guidelines recommend that physicians offer SRT to patients with PSA or local recurrence after RP in whom there is no evidence of distant metastasis (DM). ${ }^{7}$ Patients should be advised that SRT should be administered at the earliest sign of PSA recurrence. Approximately $60 \%$ of patients who are treated with SRT before the PSA level rises to $>0.5 \mathrm{ng} / \mathrm{mL}$ will achieve an undetectable PSA level, providing long-term PSA control in nearly half of them. ${ }^{8}$

However, after SRT, some patients may still experience further clinical progression, including DM and cancer-related death. The effect of SRT on the long-term outcomes including metastasis-free survival (MFS) and overall survival-especially in Chinese patients-is not well understood. Herein we report the long-term survival data of patients at a single institution in Hong Kong who received SRT to the prostatic fossa using modern RT techniques.

\section{Methods}

\section{Patient selection}

Using the MOSAIQ system (version 2.62, IMPAC Medical Systems, Inc; Sunnyvale [CA], US), we identified 91 Chinese patients treated with postoperative RT to the prostatic fossa at Tuen Mun Hospital, Hong Kong, between 2006 and 2017. The treatment records and clinical data of these patients were reviewed. Two patients who received ART with undetectable PSA were excluded. Patients who had received androgen deprivation therapy (ADT) prior to SRT were also excluded. These selection criteria yielded 84 evaluable individuals who received SRT to the prostatic fossa alone for PSA failure (defined as detection of PSA concentration at $0.2 \mathrm{ng} / \mathrm{mL}$, with a second confirmatory level detected at $0.2 \mathrm{ng} / \mathrm{mL}$ ) more than 3 months after RP.

\section{Radiation therapy techniques}

A planning computed tomographic scan was performed for each patient with 3-mm slice thickness, and the clinical target volume was determined with reference to one of the published consensus guidelines. ${ }^{9-11}$ The usual boundaries of the clinical target volume are: inferiorly, $5 \mathrm{~mm}$ below the urethral anastomosis; anteriorly, the posterior aspect of the symphysis pubis or the posterior third of the bladder; laterally, the medial border of the obturator internus and levator ani muscles; posteriorly, the anterior mesorectal fascia; and superiorly, $5 \mathrm{~mm}$ above the surgical bed. The planning target volume was defined as clinical target volume with a margin of 4 to $5 \mathrm{~mm}$

\section{根治性前列腺切除術後復發的挽救性 放射治療結果 \\ 李家齊、梅詠豪、陳偉、董煜、黃志成}

引言：挽救性放射治療（SRT）可為根治性前列腺切除術後前列腺 特異性抗原（PSA）失敗的前列腺癌患者提供有效的生化控制。然 而, SRT對長期臨床結果的影響仍不清楚。因此, 本文報告SRT治療 患者的自然病史。

方法：2006年至2017年期間於香港屯門醫院為84位華裔前列腺癌患 者進行SRT治療。我們使用Kaplan-Meier方法計算患者經治療後的生 存率, 並使用 $\log$ rank檢驗和Cox回歸確定臨床參數與結果的顯著性。

結果：中位SRT劑量為70 Gy（範圍：64-76 Gy）。中位SRT前PSA 水平為0.4 $\mathrm{ng} / \mathrm{mL}(0.2-7.4 \mathrm{ng} / \mathrm{mL}) \circ \mathrm{SRT}$ 後, 47名 $(56 \%)$ 患 者的PSA達不可檢測到的水平 $(<0.1 \mathrm{ng} / \mathrm{mL})$ 。中位隨訪 48 個月 （範圍：2個月至10年）後，25例（30\%）患者有進一步的生化惡化 進展。12名患者隨後接受雄激素剥奪治療, 9名 ( $11 \%$ ) 發生遠處轉 移。5 年無生化惡化進展生存率、無雄激素剝奪療法生存率, 以及無 轉移生存率分別為 $62.7 \%$ 、83.5\%和 $86.7 \%$ 。根治性前列腺切除術後早 期PSA失敗（危險比7.4）、陰性手術切緣（危險比2.7）、包膜外延 伸（危險比 $4.6 ） ， 以 及 S R T$ 後可檢測PSA水平（危險比 17.3 ）與SRT 後較低的無生化惡化進展存活率相關。

結論：使用調強放療 / 體積調節弧放療的高劑量SRT是有效的局部治 療方法, 能夠預防遠處轉移, 也避免根治性前列腺切除術後PSA失敗 的華裔患者須接受雄激素剝奪治療。

posteriorly and 0.7 to $1 \mathrm{~cm}$ in all other directions. Organs at risk, including the rectum, bladder, and bilateral femoral heads were contoured. Conformal radiotherapy or inverse planning techniques with intensity-modulated radiotherapy(IMRT) usingseven to nine static beams were used before October 2010 . After that, volumetric modulated arc radiotherapy (VMAT) was employed using the Pinnacle treatment planning system (Philips Medical Systems, Fitchburg [WI], US) with treatment delivered through one to two dynamic cone arcs.

\section{Variable definition}

Clinical data included age at SRT, time from surgery to RT ( $\leq 24$ months vs $>24$ months), SRT dose, pre-SRT PSA level, and post-SRT nadir PSA. Pathological data consisted of pathological T stages (T2a vs T2b vs T2c vs T3a or T3b), ECE, seminal vesicle invasion, $\mathrm{SM}$, and pathological Gleason scores $(\leq 7$ or $\geq 8)$.

\section{Outcome definition}

After SRT, patients were followed up with PSA level checks every 3 months in the first 2 years, every 6 months from year 3 to year 5, then annually. A complete response was defined as an undetectable nadir PSA $(<0.1 \mathrm{ng} / \mathrm{mL})$. Biochemical progression (PSA failure) was defined as a rise of PSA level by 0.2 
$\mathrm{ng} / \mathrm{mL}$ above the nadir with a second confirmation at least 1 week apart. ${ }^{12}$ Biochemical progressionfree survival (bPFS) was defined as the date from SRT completion to the first date of biochemical progression. Patients who showed biochemical progression or symptoms suggestive of metastasis received imaging studies at the discretion of the oncologist. Metastasis-free survival was defined as the date from SRT completion to the date of occurrence of metastasis on imaging. Patients who showed biochemical progression with or without metastasis were counselled on the use of ADT; ADT-free survival was defined as the date of SRT completion to the first date of ADT administration.

\section{Statistical analyses}

The Kaplan-Meier method was used to estimate bPFS, MFS, and ADT-free survival. Log-rank tests and Cox regression analysis were used to test the association between groups and oncologic outcomes. Covariates consisted of continuous variables, including patient age at SRT, SRT dose, and pre-SRT PSA, and discrete variables including post-SRT nadir PSA (detectable vs undetectable), pathological T stages (T2a vs T2b vs T2c vs T3a vs T3b), pathological Gleason score ( $\leq 7$ vs $\geq 8$ ), SM (negative vs positive), ECE (negative vs positive), seminal vesicle invasion (negative vs positive), and time of SRT $(\leq 24$ months after RP or $>24$ months after RP). Only variables that were significantly associated with outcomes on univariate analyses were further tested for association in multivariate analyses.

Statistical analyses were performed using IBM SPSS Statistics for Windows, version 24.0 (IBM Corp, Armonk [NY], US), and numerical data were presented according to Cole. ${ }^{13}$

\section{Results}

\section{Patients}

The median age of the 84 patients was 68 years (range, 52-79 years) when they received SRT. The patients' median pre-SRT PSA level was $0.4 \mathrm{ng} / \mathrm{mL}$ (range, $0.2-7.4 \mathrm{ng} / \mathrm{mL}$ ). Of the patients, 63 (75\%) had positive SM in their prostatectomy specimens. Extracapsular extension was detected in 25 (29.8\%) patients. Pelvic lymph nodes of 41 patients were sampled during RP and were all found to be negative for malignancy. These and other pathological characteristics are summarised in Table 1. The median time from surgery to start of SRT was 18.4 months (range, 3.8-121 months).

\section{Treatment delivery}

Before October 2010, one patient was treated with conformal RT and 10 patients were treated with IMRT. Subsequently the other 73 patients were treated with VMAT. The median dose given to the
TABLE I. Patient and RP pathological characteristics $(n=84)^{*}$

\begin{tabular}{|c|c|}
\hline & Data \\
\hline Age, y & $68(52-79)$ \\
\hline Time from RP to start of SRT, months & $18.4(3.8-121)$ \\
\hline Pre-SRT PSA, ng/mL & $0.4(0.2-7.4)$ \\
\hline \multicolumn{2}{|l|}{ Prostatectomy pathology } \\
\hline \multicolumn{2}{|l|}{ pT stage } \\
\hline Unknown & $1(1.2)$ \\
\hline $\mathrm{T} 2 \mathrm{a}$ & $8(9.5)$ \\
\hline T2b & $5(6.0)$ \\
\hline T2 & $40(47.6)$ \\
\hline T3a & $17(20.2)$ \\
\hline T3b & $13(15.5)$ \\
\hline \multicolumn{2}{|l|}{ pN stage } \\
\hline pNO & $41(48.8)$ \\
\hline $\mathrm{pNx}$ & $43(51.2)$ \\
\hline \multicolumn{2}{|l|}{ Extracapsular extension } \\
\hline Positive & $25(29.8)$ \\
\hline Negative/unknown & $59(70.2)$ \\
\hline \multicolumn{2}{|l|}{ Seminal vesicle invasion } \\
\hline Positive & $13(15.5)$ \\
\hline Negative/unknown & $71(84.5)$ \\
\hline \multicolumn{2}{|l|}{ Surgical margin } \\
\hline Positive & $63(75.0)$ \\
\hline Negative/unknown & $21(25.0)$ \\
\hline \multicolumn{2}{|l|}{ Pathological Gleason score } \\
\hline$\leq 6$ & $28(33.3)$ \\
\hline 7 & $40(47.6)$ \\
\hline$\geq 8$ & $16(19.1)$ \\
\hline
\end{tabular}

Abbreviations: PSA = prostate-specific antigen; $\mathrm{RP}=$ radical prostatectomy; SRT = salvage radiotherapy

* Data are shown as median (range) or No. (\%)

prostatic fossa was 70 Gy (range, 64-76 Gy), with 66 (79\%) patients receiving a dose of $\geq 70 \mathrm{~Gy}$. The mean dose delivered using VMAT (69.5 Gy) was slightly higher than that delivered using IMRT/conformal RT (68.1 Gy) [independent-samples $t$ test, $t=2.1$; $\mathrm{P}=0.028]$.

\section{Treatment outcome}

Of 84 patients, 47 (56\%) had undetectable PSA levels (complete response; $<0.1 \mathrm{ng} / \mathrm{mL}$ ) after SRT. After a median follow-up of 48 months (range, 2-120 months), 25 (30\%) patients had biochemical progression with an estimated 5-year bPFS of $62.7 \%$ (95\% confidence interval [CI], 50.1-75.3\%) [Fig 1a]. Among the 25 patients who developed biochemical progression after SRT, seven were found to have DM and subsequently received ADT, and five started ADT in the absence of DM, two of whom 
later developed DM and had their disease became castration-resistant. Overall, 12 patients received ADT and nine (11\%) patients developed DM. The 5-year ADT-free survival and MFS were 83.5\% (95\% CI, 73.7-93.3\%) and $86.7 \%$ (95\% CI, 77.7-95.7\%), respectively (Fig 1b, c). Notably, only six patients died, all from causes other than PCa.

\section{Biochemical progression-free survival and metastasis-free survival}

On univariate analysis, a post-SRT nadir PSA $\geq 0.1$ $\mathrm{ng} / \mathrm{mL}$, positive ECE, and bPFS $\leq 12$ months were significantly associated with a shorter MFS (all $\mathrm{P}<0.001$; Fig 2). Similarly, a post-SRT nadir PSA $\geq 0.1$ $\mathrm{ng} / \mathrm{mL}(\mathrm{P}<0.001)$, positive ECE $(\mathrm{P}<0.001)$, negative SM $(\mathrm{P}=0.045)$, pathological Gleason score $\geq 8$ $(\mathrm{P}=0.002)$, and time from surgery to $\mathrm{SRT} \leq 24$ months $(\mathrm{P}=0.008)$ were significant predictors of a shorter bPFS (Fig 3). The pre-SRT PSA level, age, and SRT dose were not associated with either MFS or bPFS in this cohort on univariate analysis. On multivariate analysis using the Cox regression method, negative $\mathrm{SM}$ (hazard ratio $[\mathrm{HR}]=2.7 ; 95 \%$ confidence interval [CI], 1.1-6.6), positive ECE $(\mathrm{HR}=4.6$; $95 \% \mathrm{CI}, 1.8$ 11.7), post-SRT nadir PSA $\geq 0.1 \mathrm{ng} / \mathrm{mL} \quad(\mathrm{HR}=17.3$; 95\% CI, 5.3-57.0), and time from surgery to SRT $\leq 24$ months $(\mathrm{HR}=7.4 ; 95 \% \mathrm{CI}, 2.2-24.0)$ retained significant association with a shorter bPFS (Table 2). There was no variable significantly associated with MFS after multivariate analysis.

\section{Discussion}

Most patients who develop biochemical recurrence after RP for localised PCa remain asymptomatic for many years. ${ }^{14}$ However, patients with increasing PSA level are at high risk of developing DM. Salvage radiotherapy is effective in terms of biochemical control when it is administered at low PSA level. Stephenson et $\mathrm{al}^{12}$ reported a 6-year progressionfree probability of $32 \%$ after SRT. In their multiinstitutional retrospective cohort of 1603 consecutive patients from 17 North American tertiary referral centres who received SRT after RP for PSA recurrence between 1987 and 2005, the median dose was only 64.8 Gy (interquartile range, 63-66 Gy) delivered using older techniques. The 5-year bPFS of $62.7 \%$ in the present study is similar or better than those reported in western countries. ${ }^{12,15,16}$ This might be due to better selection of patients (most patients started SRT when their PSA level was $\leq 0.5$ $\mathrm{ng} / \mathrm{mL}$ ), or the higher dose of SRT to the prostatic fossa (median $70 \mathrm{~Gy}$ ). In our cohort, all patients but one were treated using IMRT/VMAT. Intensitymodulated radiotherapy was introduced in the 1990s and it has since enabled radiation oncologists to deliver higher doses of radiation to treat patients with $\mathrm{PCa}$-including patients with residual disease

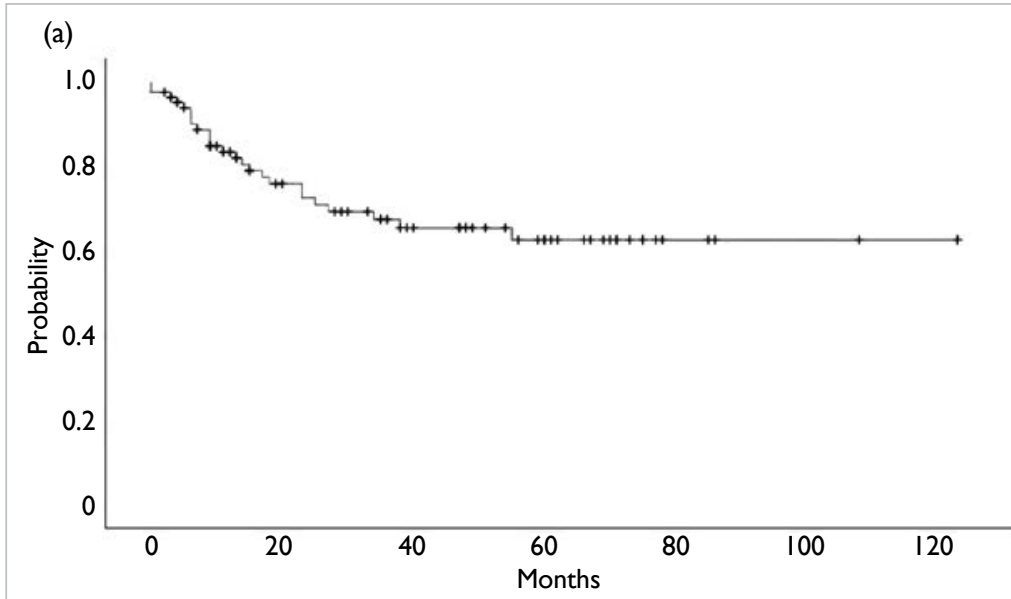

(b)

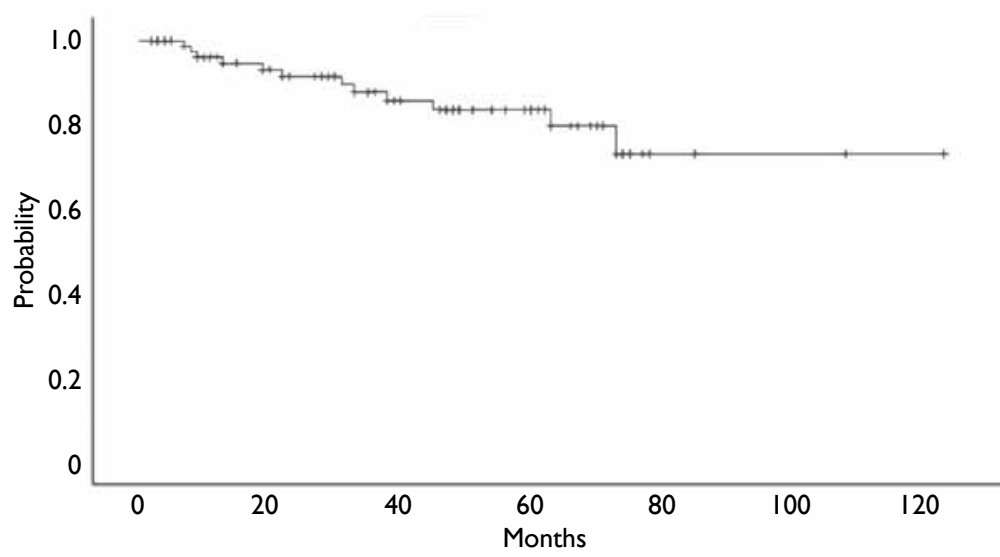

(c)

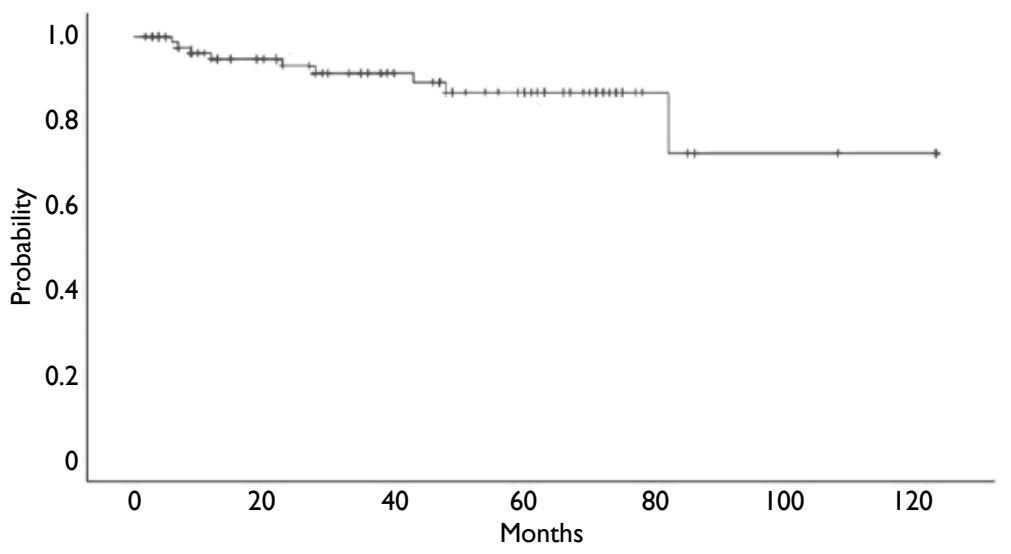

FIG I. (a) Biochemical progression-free survival, (b) androgen deprivation therapyfree survival, and (c) metastasis-free survival of patients after salvage radiotherapy

at the prostatic fossa-without causing excessive radiation damage to healthy tissue. ${ }^{17-19}$ Volumetric modulated arc radiotherapy has recently attracted much interest because it can dynamically deliver a radiation dose during rotation of the gantry; this is also superior to IMRT in terms of its plan qualities and efficiency in the treatment of $\mathrm{PCa} .{ }^{20,21}$

Pisansky et $\mathrm{al}^{22}$ reported that SRT doses of 


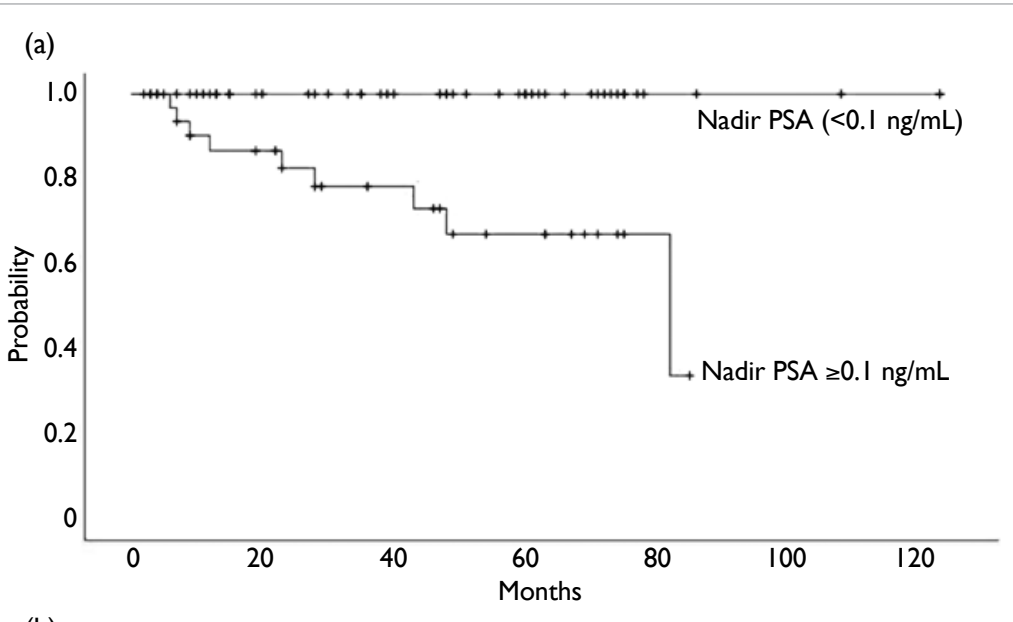

(b)

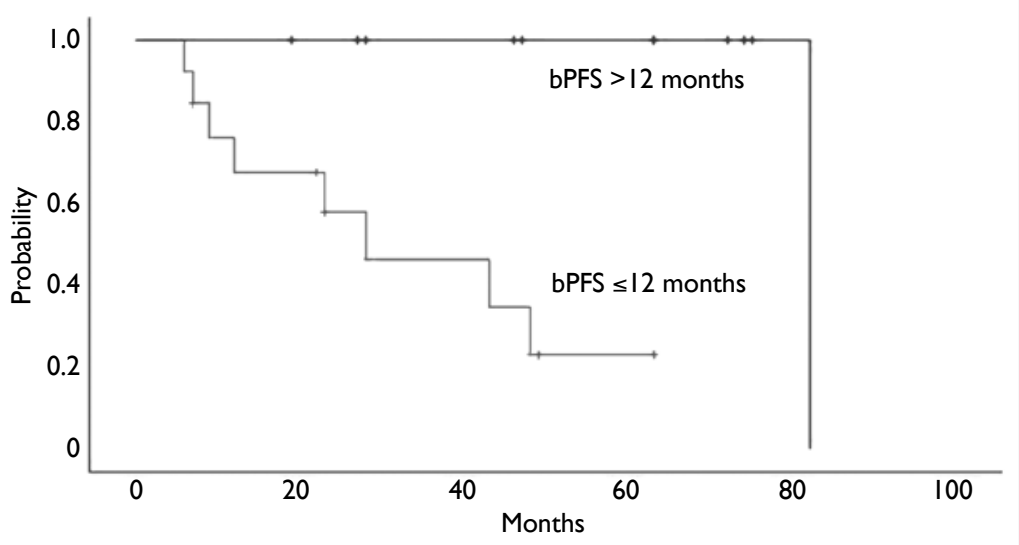

(c)

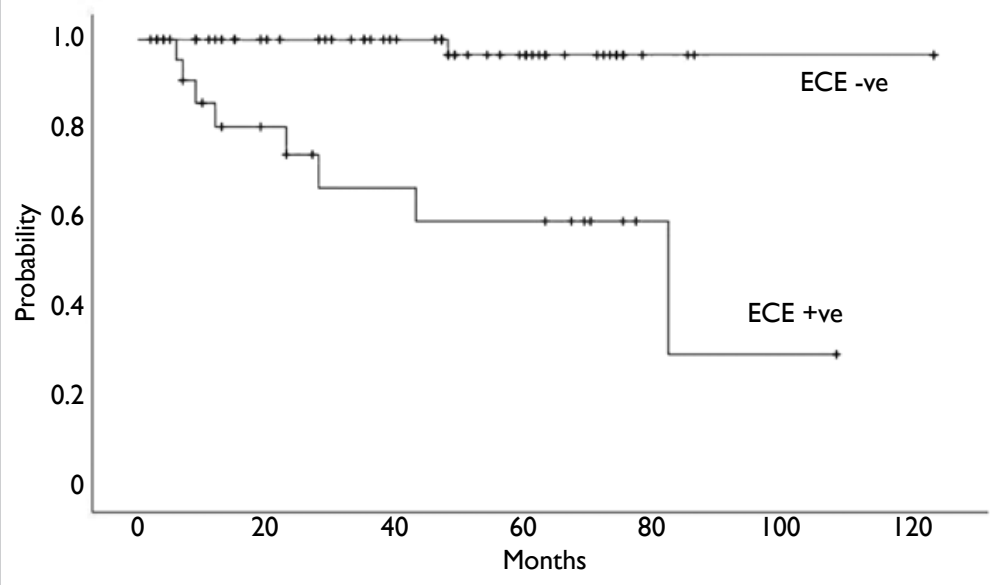

FIG 2. Metastasis-free survival by (a) nadir PSA; (b) bPFS; and (c) ECE (all P<0.00I) Abbreviations: bPFS = biochemical progression-free survival; $E C E$ = extracapsular extension; PSA = prostate-specific antigen $\geq 66.0$ Gy were associated with reduced cumulative incidence of biochemical progression. A systemic review by $\mathrm{King}^{23}$ provides level $2 \mathrm{a}$ evidence for escalated SRT dose of at least 70 Gy. A $2 \%$ improvement in relapse-free survival can be achieved for each additional Gy from $60 \mathrm{~Gy}$ to $70 \mathrm{~Gy} .^{23}$
TABLE 2. Predictive factors of shorter bPFS on multivariate analysis

\begin{tabular}{lcc}
\hline Predictive factor & $\begin{array}{c}\text { Hazard } \\
\text { ratio }\end{array}$ & $\begin{array}{c}95 \% \text { Confidence } \\
\text { interval }\end{array}$ \\
\hline Post-SRT nadir PSA $\geq 0.1 \mathrm{ng} / \mathrm{mL}$ & 17.3 & $5.3-57.0$ \\
Negative surgical margin & 2.7 & $1.1-6.6$ \\
Positive extracapsular extension & 4.6 & $1.8-11.7$ \\
Time from RP to SRT $\leq 24$ months & 7.4 & $2.2-24.0$ \\
\hline
\end{tabular}

Abbreviations: bPFS = biochemical progression-free survival; PSA = prostate-specific antigen; $\mathrm{RP}=$ radical prostatectomy; $\mathrm{SRT}=$ salvage radiotherapy

However, higher SRT dose was not shown to be associated with better bPFS/MFS in our 84 patients by univariate analysis, because most $(79 \%)$ had been treated with an SRT dose of $\geq 70$ Gy, and the followup time may still be too short to demonstrate any further dose-response relationship. We postulated that such high-dose SRT can be delivered safely with modern techniques using VMAT, therefore our current usual prescribed dose is 70 Gy to the prostatic fossa, unless limited by dose constraints of the organ at risk. We have previously shown the efficiency and low toxicities using VMAT for SRT to the prostatic fossa..$^{24}$ Longer follow-up is necessary to ensure that late complications are within safety limits.

Despite the success of SRT in biochemical control, some patients may develop further biochemical progression. In our present study, patients whose surgical pathology revealed negative margin and positive ECE had a shorter bPFS (HRs of 2.7 and 4.6, respectively). Patients who start SRT within 2 years of RP may also have a shorter PSA doubling time, leading to earlier detection of recurrence. These patients have a greater than 7 -fold higher risk of biochemical regression after SRT than those with later recurrence. Salvage radiotherapy to the prostatic fossa alone cannot eradicate cancer that has spread outside the surgical bed after RP. In fact, negative SM, positive ECE, and shorter PSA doubling time are three of the many adverse factors which predict a shorter bPFS after SRT, using the nomogram proposed by Stephenson et al. ${ }^{25}$ However, we cannot demonstrate the importance of pre-SRT PSA level in our patient cohort because more than $65 \%$ of the patients had started SRT when their PSA level was $\leq 0.5 \mathrm{ng} / \mathrm{mL}$.

Overall, the role of SRT in improving MFS and overall survival is less certain, because the disease can be indolent and mortality due to causes other than PCa is more likely in older patients. Patients also have other complications related to disease progression, such as painful bone metastasis. Efforts have been made to identify surrogate endpoints that can predict further disease progression, metastasis, and even 

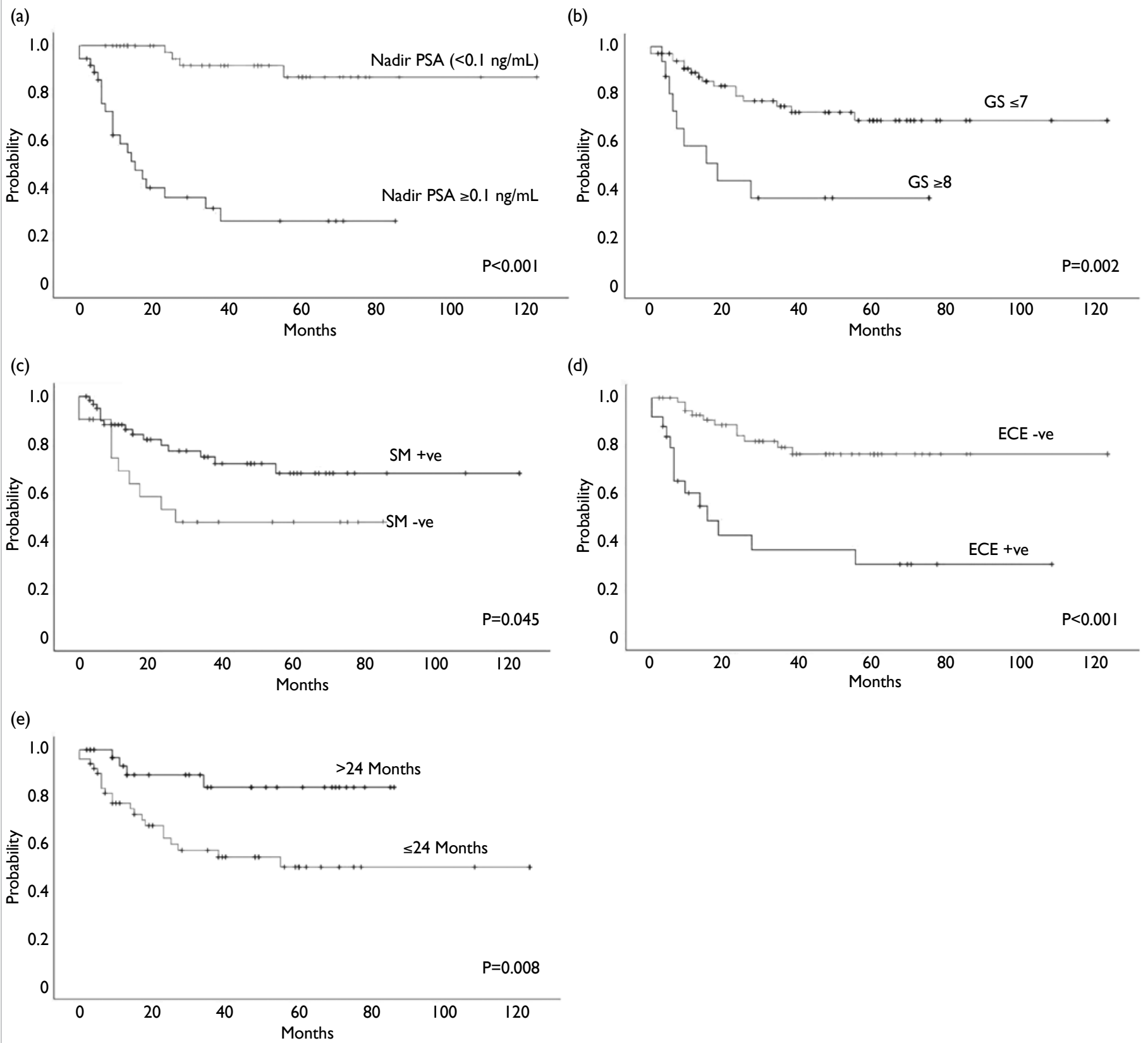

FIG 3. Biochemical progression-free survival by (a) nadir PSA; (b) GS; (c) SM; (d) ECE; and (e) time from RP to SRT

Abbreviations: $\mathrm{ECE}$ = extracapsular extension; $\mathrm{GS}=$ Gleason scores; $\mathrm{PSA}$ = prostate-specific antigen; $\mathrm{RP}=$ radical prostatectomy; $\mathrm{SM}=$ surgical margin; $\mathrm{SRT}=$ salvage radiotherapy

cancer-related death after SRT. In a single institution and overall survival. The results of our univariate review, Johnson et $\mathrm{al}^{26}$ reported approximately $50 \%$ analysis support the abovementioned findings ${ }^{27}$ of men experience further biochemical progression (Fig 2a, b). On multivariate analysis, we found after SRT. Those who have a short interval to that undetectable nadir PSA $(<0.1 \mathrm{ng} / \mathrm{mL})$ is the biochemical progression of $\leq 18$ months after SRT most important factor for predicting longer bPFS are most likely to experience DM, PCa-specific (Table 2). In the present study, of the 47 patients mortality, and overall mortality. Bartkowiak et $\mathrm{al}^{27}$ who achieved biochemical complete response after reported on the long-term outcomes of patients SRT, none developed DM. In contrast, among the with a median follow-up of 7 years (maximum, 14 25 patients who had biochemical progression, nine years) after SRT. They found that a post-SRT nadir whose disease progressed within 1 year after SRT PSA $<0.1 \mathrm{ng} / \mathrm{mL}$ was associated with improved bPFS eventually developed DM. Although our result 
TABLE 3. Pattern of disease progression

\begin{tabular}{lcll}
\hline $\begin{array}{l}\text { Patient } \\
\text { No. }\end{array}$ & $\begin{array}{c}\text { PSA when } \mathbf{~ M M ~} \\
\text { detected }(\mathbf{n g} / \mathbf{m L})\end{array}$ & Mode of imaging & Site of DM \\
\hline 1 & 6.6 & Bone scan & Multiple bone \\
\hline 2 & 9.5 & CT then C11/FDG PET & Bilateral multiple lung \\
\hline 3 & 11.1 & C11/PSMA PET & Mediastinal LNs \\
4 & 5.2 & Bone scan & Multiple bone \\
\hline 5 & 57 & C11/PSMA PET & Presacral LNs + C7 \\
6 & 3.5 & CT scan & Bilateral multiple lung \\
7 & 1.4 & C11/PSMA PET & Multiple pelvic LNs + T1 paravertebral node \\
8 & 2.2 & C11/PSMA PET & C7, L5 + presacral S3 LN + lung \\
9 & 2.7 & Plain radiography of chest and pelvis & Lung and bone \\
\hline
\end{tabular}

Abbreviations: CI I = I IC-acetate; CT = computed tomography; DM = distant metastasis; FDG = fluorodeoxyglucose; LN = lymph node; $\mathrm{PET}=$ positron emission tomography; PSA = prostate-specific antigen; PSMA = prostate-specific membrane antigen

of a 5-year MFS of nearly $90 \%$ is encouraging, with the median follow-up of only 4 years, we can hypothesise only that better biochemical control is correlated with improvements in other clinical outcomes. For patients whose PSA level does not become undetectable and rapidly rises within 1 year after SRT (bPFS $\leq 12$ months), close monitoring for DM may be needed.

The improvement in overall survival and MFS of adjuvant ADT with SRT has been demonstrated by Shipley et $\mathrm{al}^{28}$ in a phase III study. However, ADT is not routinely recommended to our patients because of the known metabolic and cardiovascular toxicities and the negative impact on patients' quality of life. In addition, most of our patients have fewer adverse features than those reported by Shipley et al. ${ }^{28}$ For patients with biochemical regression alone after SRT, we suggest monitoring for any site of disease recurrence such that further SRT could still be feasible. Nonetheless, we applied positron emission tomography with $68 \mathrm{Ga}$-labelled prostatespecific membrane antigen (PET-PSMA) to identify the site of recurrence in four of our patients when their PSA levels increased to $\geq 2.2 \mathrm{ng} / \mathrm{mL}$ (Table 3 ). All four patients were found to have DM which was not amenable to further local treatment and ADT had become their only option. It remains unclear whether PET-PSMA or other imaging studies at lower PSA levels are sensitive or useful enough to alter the management decision. ${ }^{29}$ Further research to study the use of novel radiological examinations in this situation is needed.

\section{Conclusions}

This is the first report to demonstrate the therapeutic effects in terms of bPFS and MFS of SRT in Chinese patients in a Hong Kong centre. Salvage radiotherapy is an effective local treatment that can prevent DM and avoid the need for ADT in most patients who have PSA failure after RP in Chinese patients. Our results appear to be better than those of some studies in western countries, in which older radiotherapy techniques and lower radiation doses were used. The limitations of our study include the retrospective design with lack of evaluation of patients' reported outcome, small sample size, and short duration of follow-up. A multi-institutional study is recommended to collect more local data and experiences.

\section{Author contributions}

Concept or design: EKC Lee, Y Tung.

Acquisition of data: EKC Lee, AW Chan.

Analysis or interpretation of data: EKC Lee.

Drafting of the article: EKC Lee, WH Mui, FCS Wong.

Critical revision for important intellectual content: EKC Lee, WH Mui, FCS Wong.

\section{Funding/support}

This research received no specific grant from any funding agency in the public, commercial, or not-for-profit sectors.

\section{Declaration}

All authors have no conflicts of interest to disclose. All authors had full access to the data, contributed to the study, approved the final version for publication, and take responsibility for its accuracy and integrity. An earlier version of this paper was presented as poster presentation at the 9th European Multidisciplinary Meeting on Urological Cancers, 16-19 November 2017, Barcelona, Spain.

\section{Ethical approval}

The study was conducted with approval from the New Territories West Cluster Clinical and Research Ethics Committee.

\section{References}

1. Hospital Authority, HKSAR Government. Leading cancer 
sites in Hong Kong in 2014. Available from: http://www3. ha.org.hk/cancereg/pdf/top10/rank_2014.pdf. Accessed Jul 2017.

2. Poon DM, Chan SL, Leung CM, et al. Efficacy and toxicity of intensity-modulated radiation therapy for prostate cancer in Chinese patients. Hong Kong Med J 2013;19:40715.

3. Ng AT, Tam PC. Current status of robot-assisted surgery. Hong Kong Med J 2014;20:241-50.

4. Parker C, Clarke N, Logue J, et al. RADICALS (Radiotherapy and Androgen Deprivation In Combination After Local Surgery). Clin Oncol (R Coll Radiol) 2007;19:167-71.

5. Richaud P, Sargos P, Henriques de Figueiredo B, et al. Postoperative radiotherapy of prostate cancer [in French]. Cancer Radiother 2010;14:500-3.

6. Trans Tasman Radiation Oncology Group. RAVES trial: radiotherapy-adjuvant versus early salvage. Available from: http://www.clinicaltrial.gov/ct2/show/ NCT00860652. Accessed Jul 2017.

7. Valicenti RK, Thompson I Jr, Albertsen P, et al. Adjuvant and salvage radiation therapy after prostatectomy: American Society for Radiation Oncology/American Urological Association guidelines. Int J Radiat Oncol Biol Phys 2013;86:822-8.

8. Wiegel T, Lohm G, Bottke D, et al. Achieving an undetectable PSA after radiotherapy for biochemical progression after radical prostatectomy is an independent predictor of biochemical outcome-results of a retrospective study. Int J Radiat Oncol Biol Phys 2009;73:1009-16.

9. Michalski JM, Lawton C, El Naqa I, et al. Development of RTOG consensus guidelines for the definition of the clinical target volume for postoperative conformal radiation therapy for prostate cancer. Int J Radiat Oncol Biol Phys 2010;76:361-8.

10. Poortmans P, Bossi A, Vandeputte K, et al. Guidelines for target volume definition in post-operative radiotherapy for prostate cancer, on behalf of the EORTC Radiation Oncology Group. Radiother Oncol 2007;84:121-7.

11. Sidhom MA, Kneebone AB, Lehman $M$, et al. Postprostatectomy radiation therapy: consensus guidelines of the Australian and New Zealand Radiation Oncology Genito-Urinary Group. Radiother Oncol 2008;88:10-9.

12. Stephenson AJ, Scardion PT, Kattan MW, et al. Predicting the outcome of salvage radiation therapy for recurrent prostate cancer after radical prostatectomy. J Clin Oncol 2007;25:2035-41.

13. Cole TJ. Too many digits: the presentation of numerical data. Arch Dis Child 2015;100:608-9.

14. Pound CR, Partin AW, Eisenberger MA, Chan DW, Pearson JD, Walsh PC. Natural history of progression after PSA elevation following radical prostatectomy. JAMA 1999;281:1591-7.

15. Geinitz H, Riegel MG, Thamm R, et al. Outcome after conformal salvage radiotherapy in patients with rising prostate-specific antigen levels after radical prostatectomy. Int J Radiat Biol Oncol Phys 2012;82:1930-7.

16. Fossati N, Karnes RJ, Boorjian SA, et al. Long-term impact of adjuvant versus early salvage radiation therapy in pT3N0 prostate cancer patients treated with radical prostatectomy: results from a multi-institutional series. Eur Urol 2017;71:886-93.

17. Goldin GH, Sheets NC, Meyer A, et al. Patterns of intensity modulated radiation therapy (IMRT) use for the definitive and postoperative treatments of prostate cancer: a SEERmedicare analysis. Int J Radiat Oncol Biol Phys 2011;81(2 Suppl):S408.

18. Nath SK, Sandhu AP, Rose BS, et al. Toxicity analysis of postoperative image-guided intensity-modulated radiotherapy for prostate cancer. Int J Radiat Oncol Biol Phys 2010;78:435-41.

19. Ost P, De Troyer B, Fonteyne V, Oosterlinck W, De Meerleer G. A matched control analysis of adjuvant and salvage high-dose postoperative intensity-modulated radiotherapy for prostate cancer. Int J Radiat Oncol Biol Phys 2011;80:1316-22.

20. Kopp RW, Duff M, Catalfamo F, Shah D, Rajecki M, Ahmad K. VMAT vs. 7-field-IMRT: assessing the dosimetric parameters of prostate cancer treatment with a 292-patient sample. Med Dosim 2011;36:365-72.

21. Palma D, Vollans E, James K, et al. Volumetric modulated arc therapy for delivery of prostate radiotherapy: reduction in treatment time and monitor unit requirements compared to intensity modulated radiotherapy. Int J Radiat Oncol Biol Phys 2008;72(1 Suppl):S312.

22. Pisansky TM, Agrawal S, Hamstra DA, et al. Salvage radiation therapy dose response for biochemical failure of prostate cancer after prostatectomy-A multi-institutional observational study. Int $J$ Radiat Oncol Biol Phys 2016;96:1046-53.

23. King CR. The dose-response of salvage radiotherapy following radical prostatectomy: a systemic review and meta-analysis. Radiother Oncol 2016;121:199-203.

24. Lee EK, Yuen KK, Mui WH, et al. Salvage radiotherapy to the prostatic fossa using volumetric-modulated arc therapy: early results. Hong Kong J Radiol 2013;16:191-7.

25. Stephenson AJ, Shariat SF, Zelefsky MJ, et al. Salvage radiotherapy for recurrent prostate cancer after radical prostatectomy. JAMA 2004;291:1325-32.

26. Johnson $\mathrm{S}$, Jackson $\mathrm{W}, \mathrm{Li} \mathrm{D}$, et al. The interval to biochemical failure is prognostic for metastatic, prostate cancer-specific mortality, and overall mortality after salvage radiation therapy for prostate cancer. Int J Radiat Oncol Biol Phys 2013;86:554-61.

27. Bartkowiak D, Bottke D, Thamm R, Siegmann A, Hinkelbein W, Wiegel T. The PSA-response to salvage radiotherapy after radical prostatectomy correlates with freedom from progression and overall survival. Radiother Oncol 2016;118:131-5.

28. Shipley WU, Seiferheld W, Lukka HR, et al. Radiation with or without antiandrogen therapy in recurrent prostate cancer. N Engl J Med 2017;376:417-28.

29. Perera M, Papa N, Christidis D, et al. Sensitivity, specificity, and predictors of positive 68Ga-prostate-specific membrane antigen positron emission tomography in advanced prostate cancer: a systemic review and metaanalysis. Eur Urol 2016;70:926-37. 